\title{
A Clinical Study to Know the Effect of Chlorhexidne Mouth Wash on Radiation Induced Oral Mucositis
}

\section{Kishore Kumar $\mathbf{M}^{*}$}

Department of Pharmacology, Samskruthi College of Pharmacy, Jawaharlal Nehru Technological University, Hyderabad, Telangana 500085, India

\begin{abstract}
This Research article mainly based on the introduction of oral mucositis.Mucositis is the painful inflammation and ulceration of the mucous membranes lining the digestive tract, usually as an adverse effect of chemotherapy and radiotherapy treatment for cancer. Mucositis can occur anywhere along the gastrointestinal $(\mathrm{Gl})$ tract, but oral mucositis refers to the particular inflammation and ulceration that occurs in the mouth. Oral mucositis is a common and often debilitating complication of cancer treatment. There are different stages involved in the oral mucositis, oral mucositis is mainly due to the post chemo-treatment in the cancer. There are several drugs used in the cancer treatment which causes a lot of side effects and of that oralmucositis is one and the drug used below to cure oral mucositis is chlorhexidine mouth wash and it plays a vital role in the treatment of oral mucositis. The safety and efficacy of the drug is clearly demonstrated by comparison with the rest of the drugs in the market.
\end{abstract}

Keywords: Radiation; oral mucositis; Cancer

\section{Introduction}

Oral mucositis represents a major non hematologic complication of cytotoxic chemotherapy and radiotherapy associated with significant morbidity, pain, odynodysphagia, dysgeusia, and subsequent dehydration and malnutrition which reduce the quality of life of affected person. The term oral mucositis emerged in the late $1980 \mathrm{~s}$ to describe the CT \& RT induced inflammation of oral mucosa. Oral mucositis, also called stomatitis, is a common, debilitating complication of cancer chemotherapy and radiotherapy, occurring in about $40 \%$ of patients. It results from the systemic effects of cytotoxic chemotherapy agent sand from the local effects of radiation to the oral mucosa. Oral mucositis is inflammation of the mucosa of the mouth which ranges from redness to severe ulceration. Symptoms of mucositis vary from pain and discomfort to an inability to tolerate food or fluids. Mucositis may also limit the patient's ability to tolerate either chemotherapy or radiotherapy. Mucositis may be so severe as to delay treatment and so limit the effectiveness of cancer therapy. Patients with damaged oral mucosa and reduced immunity resulting from chemotherapy and radiotherapy are also prone to opportunistic infections in the mouth. The mucositis may affect patients' gum and dental condition, speech and self-esteem are reduced, further compromising patients' response to treatment and/or palliative care. It is therefore extremely important that mucositis be prevented whenever possible, or at least treated to reduce its severity and possible complications. Currently there is a bewildering number of interventions to choose from, but no high quality synthesis of the best research evidence for these interventions. This Best Practice Information Sheet has been developed to present the best available evidence related specifically to the prevention and treatment of oral mucositis induced by chemotherapy or radiotherapy in cancer patients [1].

\section{Compound}

Chlorhexidine Gluconate is Biguanide and chlorhexidine is an important antiseptic, disinfectant, pharmaceutical and cosmetic preservative and ant plaque agent.It exist as the acetate (diacetate), gluconate and hydrochloride salts, Bacteriostatic in low concentration and bactericidal in high concentration. More effective in alkaline than acidic $\mathrm{pH}$, Activity reduced in presence of organic matter. It is sporostatic but not sporicidal towards bacterial spores (Figure 1).

\section{Materials and Methods}

\section{Method}

Estimation of dental parameters: (plaque index and gingival index): Index was described by SILNESS P., LOE H. in 1964PI [2-4]. Plaque of cervical third of the tooth is evaluated (Four surfaces are examined Distal-facial) (Figures 2-4). The Microbiological assessment of $10 \mathrm{ml}$ sterile saline containing mouth rinse in a sterile vial in $1 \mathrm{ml}$ of sample was diluted in $9 \mathrm{ml}$ of BHI suspension was plated out on to $5 \%$ sheep blood agar, Mcconkey 3 agar, yeast morphology agar. The agar plates of BHI broth incubated for 72 hours aerobically at $37^{\circ} \mathrm{C}$ in

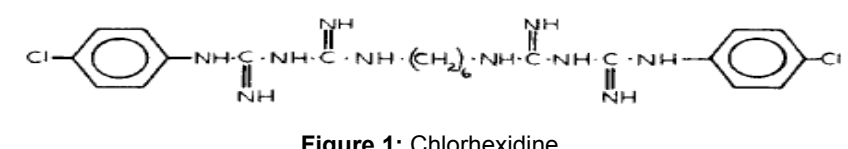

Figure 1: Chlorhexidine.

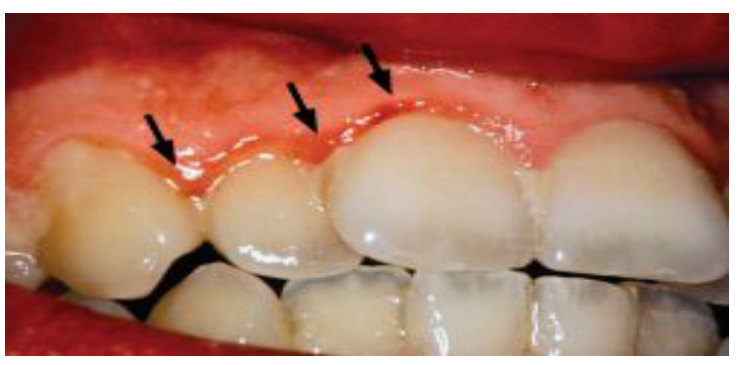

Figure 2: Gingival Margin

*Corresponding author: Kishorekumar M, Department of Pharmacology, Samskruthi College of Pharmacy, Jawaharlal Nehru Technological University, Hyderabad, Telangana -500085, India, E-mail: Kishore_kumar253@yahoo.com

Received: April 07, 2015; Accepted: April 22, 2015; Published: April 29, 2015

Citation: Kishore Kumar M (2015) A Clinical Study to Know the Effect of Chlorhexidne Mouth Wash on Radiation Induced Oral Mucositis. J Bioengineer \& Biomedical Sci 5: 150. doi:10.4172/2155-9538.1000150

Copyright: ( 2015 Kishore Kumar M. This is an open-access article distributed under the terms of the Creative Commons Attribution License, which permits unrestricted use, distribution, and reproduction in any medium, provided the original author and source are credited. 


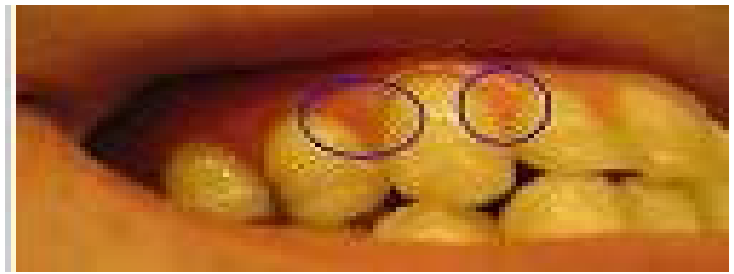

Figure 3: Gingival Papilla.

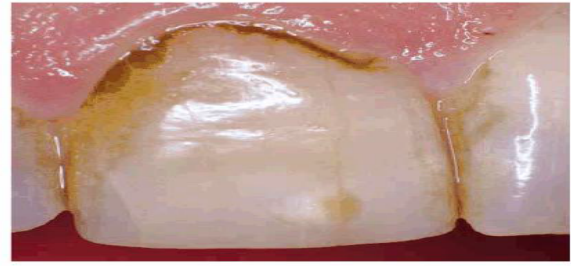

Figure 4: Cervical Third of Tooth.

$5 \% \mathrm{CO}_{2}$. By counting the plates after incubation the numberof micro organism per milliliter was estimated Colonization Index-Colonisation index of the oral cavity was defined as the sum of logarithms of the concentration of a particular microorganism isolated from $1 \mathrm{ml}$ of oral washing specimens divided by the number of oral washing.

\section{Results}

Results shown in Tables 1-5 and Figures 5-9.

\section{Discussion}

The efficacy analysis was based on all patients treated population using ANOVA by using Graph pad Prism V.5.03 in M.S Office 2007 platform. Analysis (Table 1) shows that out of 20 subjects in the CHX treated group $90 \%$ subjects were getting complete response with significant decrease in plaque index as compared to the PVI treated group and placebo treated group which shows the marked efficacy of $\mathrm{CHX}$ in the reduction of plaque during mucositis $(\mathrm{p}<0.01)$. Analysis [5-8] of observation, Table 2 shows the superior result of CHX study group during the assessment of gingival index which significantly reduce the severity of gingivitis $(\mathrm{p}<0.01)$. Analysis of observation Table 3 shows the remarkable changes found in the salivary flow rate in the CHX treated group with the significant result $(\mathrm{p}<0.01)$. In mucositic condition the $\mathrm{pH}$ of saliva was decreased and became acidic due to the ulcerative surface of oral mucosal cavity and the acidic $\mathrm{pH}$ of saliva become neutral significantly with the treatment of CHX mouth rinse over 28 days study period as compare to the other groups $(\mathrm{p}<0.01)$. Analysis of observation, Table 5 shows significant reduction in the colonisation index in the CHX treated group after the estimation of number of microorganism per millilitre by reading and counting the plates after incubation. Sum of logarithms of the concentration of gram negative bacilli and Candida species isolated from $1 \mathrm{ml}$ of oral washing specimens was divided by the number of oral washing to get that index. In this case the ANC was measured by regular blood testing of the admitted patients in the hospital $[9,10]$. During our study period the neutrophil count was significantly increased in the CHX treated group within 10 days but in PVI treated group it was taking 13 to 15 days. So group 2 (CHX) subjects were having comparatively less no of days to increase in ANC count (ANC>1500) than the group 3 (PVI) treated group. The CHX treatment group shows less adverse events in comparison to PVI treated group (Irritation, swelling, erythema) but the adverse events such as loss of taste perception and staining was seen in more in group 2 patients than group 3 patients. At last the Table 5 shows the response rate of the various treatment (CHX) patients shows $90 \%$ complete response, $10 \%$ partial response where as the group 3 (PVI) patients shows 70\% complete response, 25\% partial response and $5 \%$ no response [11-13]. It was proved that the $\mathrm{CHX}$ mouth rinse was more effective than PVI solution in the treatment of mucositis.

\begin{tabular}{|c|c|c|c|}
\hline Group/visit & $\begin{array}{c}\text { visit 1 (With the } \\
\text { starting of RT) } \\
\text { (Base line Visit) }\end{array}$ & $\begin{array}{c}\text { Visit 2 } \\
\text { ( After 14 days) }\end{array}$ & $\begin{array}{c}\text { Visit 3 } \\
\text { ( After 28 Days) }\end{array}$ \\
\hline Group 1 ( Placebo) & $0.109-1.897$ & $0.089-2.390$ & $0.075-2.839$ \\
\hline Group 2 (CHX) & $0.124-2.052$ & $0.096-1.271$ & $0.0488-0.256$ \\
\hline Group 3(PVI) & $0.525-2.554$ & $0.100-1.362$ & $0.075-0.089$ \\
\hline
\end{tabular}

Table 1: Plaque index of study subjects over a period of 4 weeks.

\begin{tabular}{|c|c|c|c|}
\hline Group/visit & $\begin{array}{c}\text { visit 1 (With the } \\
\text { starting of RT) } \\
\text { (Base line Visit) }\end{array}$ & $\begin{array}{c}\text { Visit 2 } \\
\text { ( After 14 days) }\end{array}$ & $\begin{array}{c}\text { Visit 3 } \\
\text { ( After 28 Days) }\end{array}$ \\
\hline Group 1 ( Placebo) & $0.108-2.118$ & $0.076-2.647$ & $0.053-3.056$ \\
\hline Group 2 (CHX) & $0.105-1.905$ & $0.082-1.237$ & $0.060-0.356$ \\
\hline Group 3(PVI) & $0.126-2.081$ & $0.116-1.379$ & $0.099-0.835$ \\
\hline
\end{tabular}

Table 2: Gingival Index of Study Subjects over a Period of 4 Weeks.

\begin{tabular}{|c|c|c|c|}
\hline Group/visit & $\begin{array}{c}\text { visit 1 (With the } \\
\text { starting of RT) } \\
\text { (Base line Visit) }\end{array}$ & $\begin{array}{c}\text { Visit 2 } \\
\text { ( After 14 days) }\end{array}$ & $\begin{array}{c}\text { Visit 3 } \\
\text { ( After 28 Days) }\end{array}$ \\
\hline Group 1 ( Placebo) & $0.028-0.520$ & $0.024-0.400$ & $0.018-0.211$ \\
\hline Group 2 (CHX) & $0.023-0.410$ & $0.039-0.860$ & $0.053-1.440$ \\
\hline Group 3(PVI) & $0.023-0.425$ & $0.025-0.620$ & $0.051-0.970$ \\
\hline
\end{tabular}

Table 3: Salivary flow rate of study subjects over a period of 4 weeks.

\begin{tabular}{|c|c|c|c|}
\hline Group/visit & $\begin{array}{c}\text { visit 1 (With the } \\
\text { starting of RT) } \\
\text { (Base line Visit) }\end{array}$ & $\begin{array}{c}\text { Visit 2 } \\
\text { ( After 14 days) }\end{array}$ & $\begin{array}{c}\text { Visit 3 } \\
\text { ( After 28 Days) }\end{array}$ \\
\hline Group 1 ( Placebo) & $0.028-0.520$ & $0.024-0.400$ & $0.018-0.211$ \\
\hline Group 2 (CHX) & $0.023-0.410$ & $0.039-0.860$ & $0.053-1.440$ \\
\hline Group 3(PVI) & $0.023-0.425$ & $0.025-0.620$ & $0.051-0.970$ \\
\hline
\end{tabular}

Table 4: Salivary flow rate of study subjects over a period of 4 weeks.

\begin{tabular}{|c|c|c|c|}
\hline Group/visit & $\begin{array}{c}\text { visit 1 (With the } \\
\text { starting of RT) } \\
\text { (Base line Visit) }\end{array}$ & $\begin{array}{c}\text { Visit 2 } \\
\text { (After 14 days) }\end{array}$ & $\begin{array}{c}\text { Visit 3 } \\
\text { (After 28 Days) }\end{array}$ \\
\hline Group 1 ( Placebo) & $0.155-5.025$ & $0.196-4.475$ & $0.124-3.397$ \\
\hline Group 2 (CHX) & $0.137-4.575$ & $0.162-6.650$ & $0.125-7.050$ \\
\hline Group 3(PVI) & $0.167-5.325$ & $0.105-5.975$ & $0.098-6.300$ \\
\hline
\end{tabular}

Table 5: Salivary $\mathrm{pH}$ of study subjects over a period of 4 weeks.

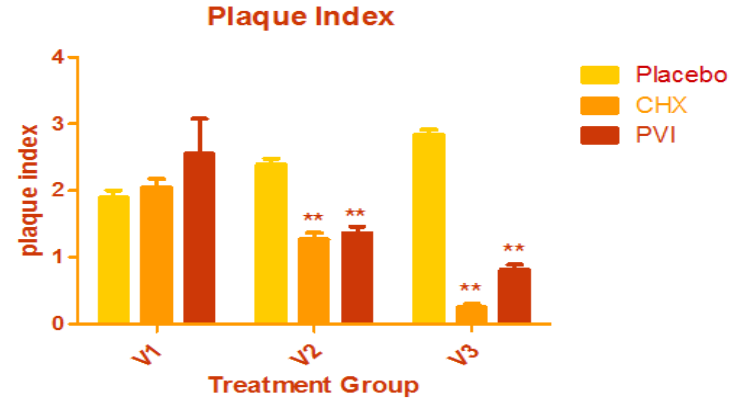

Figure 5: Plaque index over a period of 4 weeks. 


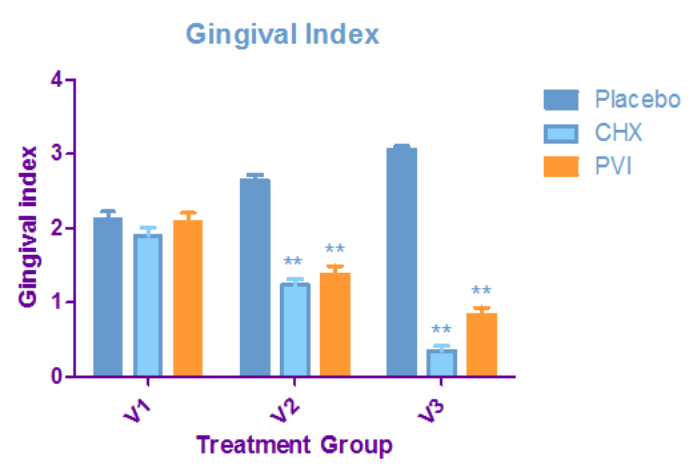

Figure 6: Gingival index vs. treatment group over a period of 4 weeks.

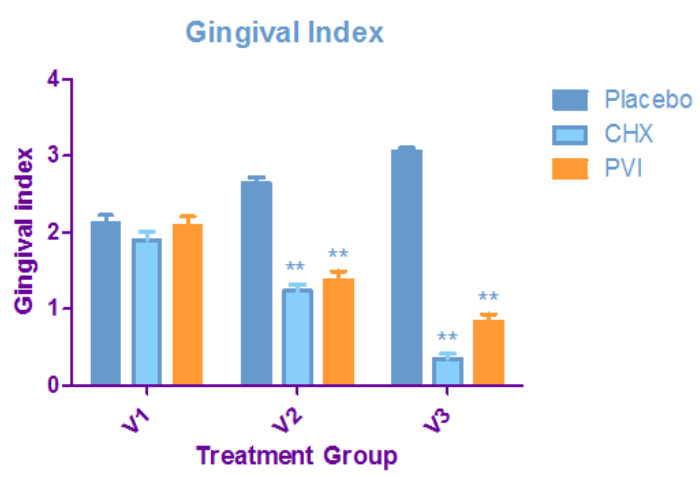

Figure 7: Gingival index over a period of 4 weeks.

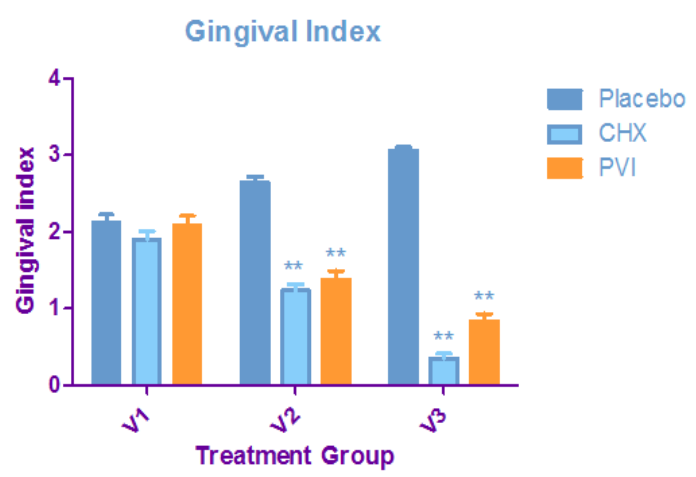

Figure 8: Gingival index over a period of 4 weeks.

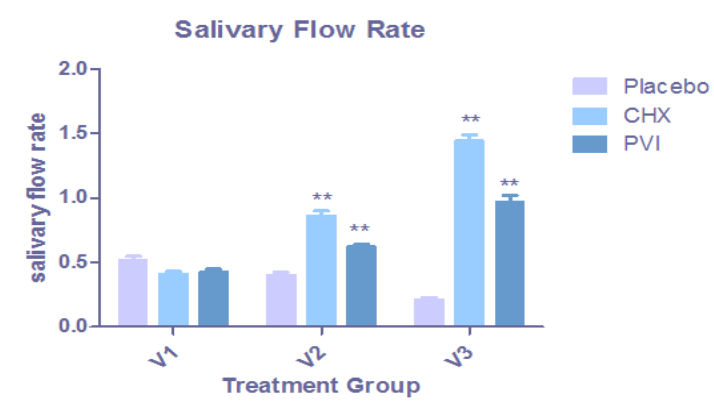

Figure 9: Salivary flow rate of study subjects over a period of 4 weeks.

\section{Conclusion}

From the encrypted data obtained during this trial, it can be clearly summarized that by comparative clinical study of CHX with PVI, it was found that superior antibacterial effect of $\mathrm{CHX}$ reduces the severity of mucositis during the CT and RT therapy of head and neck cancer patients with less chances adverse events. CHX- Use as antiseptic rinse helps in prophylaxis also prevents the side effects of RT and CT like oral mucositis; pain full oral ulcers and gingivitis by preventing the growth of micro organism and by increasing salivary flow.

\section{References}

1. Bensadoun RJ, Magne N (2001) Chemotherapy induced mucositis in head and neck cancer patients: new trends in pathophysiology, preventation and treatment. Spingerverlag 258: 481-487.

2. Cox JD, Steiy J (1995) Toxicity criteria of the Radiation Therapy Oncology Group (RTOG) and the European Organization for Research and Treatment of Cancer (EORTC). Int J Radiat Oncol Biol Phys 31: 1341-1346.

3. Denham JW, Abbott RL (1991) Concurrent cisplatin, infusion fluorouracil, and conventionally fractionated radiation therapy in head and neck cancer: Doselimiting mucosal toxicity. J Clin Oncol 9: 458-463.

4. Deorukhkar A, Krishna S (2010) Targeting inflammatory pathways for tumour radio sensitization. Biochem Pharmacol 80: 1904-1914.

5. Haagen J, Krohn H, Röllig S, Schmidt M, Wolfram K, et al. (2009) Effect of selective inhibitors of inflammation on oral mucositis: Preclinical studies. Radiother Oncol 92: 472-476.

6. Sonis ST (2002) The biologic role for nuclear factor-kB in disease and its potential involvement in mucosal injury associated with anti-neoplastic therapy. Crit Rev Oral Biol Med 13: 380-389.

7. Sonis ST, Tracey C (1990) An animal model for mucositis induced by cancer chemotherapy. Oral Surg Oral Med Oral Pathol 69: 437-443.

8. Roberts WR, Addy M (1981) Comparison of in vitro and in vivo antibacteria properties of antiseptic mouth rinses containing chlorhexidine, alexidine cetylpyridium chloride and hexetidine, Relevance to mode of action. J Clin Periodontol 8: 295-310.

9. Shalamanov DS (2005) Chlorhexidine Gluconate induced morphologica changes in gram negative micro-organisim. Biotechnol and Biotechnol Eq 19: 121-124.

10. Loe H, Theilade E (1967) Experimental gingivitis in man. The influence of antibiotic on gingival plaque development. J Periodontal Res 2: 282-289.

11. Rubenstein EB, Peterson DE, Schubert M, Keefe D, McGuire D, et al. (2004) Mucositis Study Section of the Multinational Association for Supportive Care in Cancer. International Society for Oral Oncology.

12. McGuire DB, Fulton JS, Park J, Brown CG, Correa ME, et al. (2013) Mucositis Study Group of the Multinational Association of Supportive Care in Cancer/ International Society of Oral Oncology (MASCC/ISOO). Support Care Cancer.

13. Cirillo N (2013) Prevention of fibroblast senescence by hyaluronic acid and clinical application to chemoradiation-induced oral mucositis. Proceedings of 3rd World Congress on Cancer Science \& Therapy, Australia. 